Fourth International Conference on Sustainable Construction Materials and Technologies http://www.claisse.info/Proceedings.htm

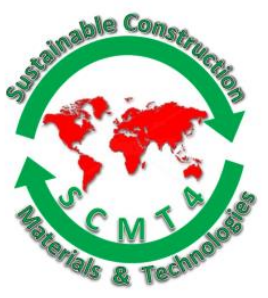

SCMT4

Las Vegas, USA, August 7-11, 2016

\title{
Investigation of Microwave Healing Performance of Electrically Conductive Carbon Fiber Modified Asphalt Mixture Beams
}

\author{
Zigeng Wang ${ }^{1 \mathrm{a}}$, Qingli Dai ${ }^{1 \mathrm{~b}}$, Zhanping You ${ }^{1 \mathrm{c}}$, and David Porter ${ }^{1 \mathrm{~d}}$ \\ ${ }^{1}$ Department of Civil and Environmental Engineering, Michigan Technological University, 1400 Townsend

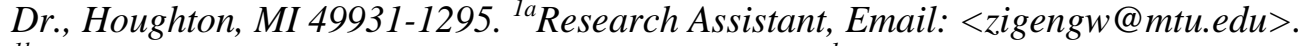 \\ ${ }^{1 b}$ Assistant Professor, Email: <qingdai@mtu.edu>., ${ }^{1 c}$ Professor,Email: <zyou@mtu.edu>. \\ ${ }^{1 d}$ Research Assistant, Email: <dporter@mtu.edu>.
}

\begin{abstract}
This presented paper aimed to investigate the physical properties and microwave-healing performance of carbon fiber modified asphalt mixture. Two types of carbon fibers, HexTow® IM8 and AS4 (from HEXCEL Company), were added to asphalt mixture. About $2 \%$ and $4 \%$ HexTow ${ }^{\circledR}$ IM8 fiber (by mixture weight) were chopped and dry-mixed for the modified asphalt mixture. About $1.5 \%$ and $3 \%$ of HexTow ${ }^{\circledR}$ AS4 fiber (by binder weight) were pre-cut and wet-mixed with asphalt binder then the modified asphalt mixture was produced. The thermal conductivity of carbon fiber modified asphalt mixture samples increased. The electrical resistivity of them decreased with fiber content. In addition, the cyclic fracturemicrowave healing tests were conducted to evaluate the healing performance of the control and carbon fibers modified asphalt mixture samples. The test results, namely the original strengths and recovered strengths, indicated that the original strength of the carbon fiber modified asphalt mixture decreased slightly. The carbon fiber modified asphalt mixture can achieve superior healing performance with microwave healing approach.
\end{abstract}

\section{INTRODUCTION}

The asphalt mixture is a composite material of air void, asphalt binder and aggregates of various shapes and sizes (You, Adhikari et al. 2009). The binder and mixture present viscoelastic and thermoplastic characteristics(Si, Ma et al. 2014). Due to the sensitivity to temperature and moisture, the performance and serviceability of pavements are prone to deteriorate than other infrastructures (Ma, Si et al. 2014). One main reason is that the microcracks develop in the asphalt mixture (Liu, Schlangen et al. 2010). Therefore, the pavement surface layer needs to be maintained frequently.

Asphalt mixture has the ability to repair its damage during the service life called self-healing (García, Schlangen et al. 2012). But the healing process is limited by two factors, temperature and rest periods (Kim, Little et al. 2003, García, Schlangen et al. 2012). When the external energy is input to heat thermoplastic asphalt binder, microcracks generated by the traffic and environmental loadings could be healed (Wang, Dai et al. 2016). This is called the induced healing behavior that can accelerate the self-healing process. The self-healing behavior is a complicated process combined with capillary flow, molecules wetting and intermolecular diffusion studied by Shen et al. (Shen, Chiu et al. 2010). 
Carbon fiber, as a type of modifier, was added to asphalt material to investigate the performance by many researchers. Yang et al. (Yang, Yang et al. 2011) utilized carbon fiber into the transportation system to improve the deicing technology. Liu et al. (Liu, Wu et al. 2008) proposed that the conductive asphalt concrete within graphite and carbon fiber was valid for the self-monitoring of strain and stress. In addition, after measuring the mechanical and electrical properties of graphite and carbon fiber modified asphalt concrete, Liu and $\mathrm{Wu}$ (Liu and $\mathrm{Wu} 2011$ ) found the carbon fiber could increase the Marshall stability, residual stability and rutting dynamic stability. Some scientists studied the relationship between the carbon fiber and microwave. For instance, Qing et al. (Qing, Zhou et al. 2010) investigated the microwave electromagnetic properties of carbon fiber as conductive absorber filled insulating epoxy/silicone resin coatings and the complex permittivity of the coatings increased when the content of carbon fiber increased. The microwave absorbing properties of the composites containing inductive activated carbon fiber screens (IACFFSs) were affected by the element configurations of IACFFSs, found by Zhao et al. (Zhao, Zou et al. 2006).

The objective of this research is to investigate the thermal property, electrical property and microwave healing performance of the carbon fiber modified asphalt mixture. First, HexTow ${ }^{\circledR}$ IM8 was blended with asphalt and aggregates by dry process. HexTow ${ }^{\circledR}$ AS4 were added to the asphalt at first, then mixed with aggregates to produce the beam samples, namely the wet process. Afterwards, the thermal conductivity and electrical resistivity of the samples were measured and calculated, respectively. Finally, the cyclic fracturemicrowave healing tests were implemented to evaluate the healing performance of the samples.

\section{MIXTURE DESIGN AND SAMPLE PREPARATION}

In this research, five types of asphalt mixture samples were prepared as the tested samples, including control, IM8 carbon fiber ( $2 \%$ and $4 \%$ by weight of asphalt mixture) modified and AS4 carbon fiber (1.5\% and $3 \%$ by weight of asphalt binder) modified asphalt mixture, respectively.

\section{Control and carbon fiber modified mixture design}

The asphalt binder used in the mixture was PG 58-28 with a density of $1.024 \mathrm{~g} / \mathrm{cm}^{3}$. The aggregates consisting of mixture were from Hancock, Michigan with an average density of $2.72 \mathrm{~g} / \mathrm{cm}^{3}$. The amount of asphalt used for the mixture samples was $5.7 \%$ by weight of the mixture determined by the test of the optimum asphalt content based on Superpave 5E1 mix design. The aggregate gradation of the asphalt mixture is shown in Table 1.

Table 1. Aggregate gradation of asphalt mixture

\begin{tabular}{|l|l|l|l|}
\hline Sieve Number & Sieve Size $(\mathrm{mm})$ & \% Retained & Mass $(\mathrm{g})$ \\
\hline $1 / 2$ inch & 12.5 & 1.3 & 720.0 \\
\hline $3 / 8$ inch & 9.5 & 12.2 & 924.0 \\
\hline No. 4 & 4.75 & 14.7 & 2172.0 \\
\hline No. 8 & 2.36 & 20.4 & 2280.0 \\
\hline No. 16 & 1.18 & 15.3 & 1296.0 \\
\hline No. 30 & 0.6 & 10.6 & 1272.0 \\
\hline No. 50 & 0.3 & 10.8 & 1536.0 \\
\hline No. 100 & 0.15 & 7 & 996.0 \\
\hline No. 200 & 0.075 & 2.3 & 264.0 \\
\hline Pan & $<0.075$ & 5.4 & 540.0 \\
\hline
\end{tabular}

The carbon fibers used were HexTow IM8 and AS4, from Hexcel Co.. IM8 carbon fiber is a continuous, polyacrylonitrile (PAN) based fiber in 12,000 filament count tows. The tensile strength is 6,067 MPa. The 
tensile modulus (Chord 6000-1000) is $310 \mathrm{GPa}$. The ultimate elongation at failure is $1.8 \%$. The density is $1.78 \mathrm{~g} / \mathrm{cm}^{3}$. The filament diameter is 5.2 microns. All the IM8 carbon fibers were first chopped to $6.35 \mathrm{~mm}$ then dry mixed with the asphalt mixture. The amount used of IM8 was $2 \%$ and $4 \%$ based on the asphalt weight. AS4 carbon fiber is a pre-chopped, PAN based fiber in 3000 filament count tows. The tensile strength is $4619 \mathrm{MPa}$. The tensile modulus (Chord 6000-1000) is $231 \mathrm{GPa}$. The ultimate elongation at failure is $1.8 \%$. The density is $1.79 \mathrm{~g} / \mathrm{cm}^{3}$. The filament diameter is 7.1 microns. All the AS4 carbon fibers were pre-chopped with length about $6.35 \mathrm{~mm}$ and also sized to improve fracture strength. The amount of added AS4 was $1.5 \%$ and 3\% based on asphalt binder weight. These fibers were first mixed with asphalt binder at an elevated temperature to melt the sizing materials. The carbon fiber modified binder was then used to prepare the asphalt mixtures.

\section{Mixture beam sample preparation}

In this study, the samples used were beams with a length of $190 \mathrm{~mm}$, width of $50 \mathrm{~mm}$ and height of $69 \mathrm{~mm}$. In addition, a $23 \mathrm{~mm}$ deep, $3 \mathrm{~mm}$ wide notch was sawn in the center of the beams to control the initial cracking position. For each beam sample, two knife edges were glued on the top notch for measuring the crack tip opening displacement by a clip-on gauge. Consequently, 3 beam samples were prepared for each mixture type, control, 2\% and 4\% IM8 modified, $1.5 \%$ and 3\% AS4 modified asphalt mixture beam samples. Therefore, 15 beam samples were produced for the whole cyclic fracture-microwave healing tests discussed in the following sections.

\section{THERMAL AND ELECTRICAL PROPERTIES MEASUREMENT OF ASPHALT MIXTURE}

\section{Thermal conductivity of asphalt mixture beams}

In this study, a KD2 Pro thermal property analyzer from Decagon Devices Inc. was utilized to measure the thermal conductivity of carbon fiber modified asphalt mixture samples based on transient line heal source methods, displayed in Fig. 1(a) (Vacquier 1985, D5334-14 2014). The heat generated by a needle TR-1 sensor (length of $10 \mathrm{~cm}$, diameter of $2.4 \mathrm{~mm}$ ) inside the sample formed gradient temperature. Then the sensor detected the temperature variation and recorded the data. The thermal conductivity was calculated by Equation (1) and (2):

$T=m_{0}+m_{1} t+m_{2} \ln t$

where $T$ is the recorded temperature, $m_{0}$ denotes the environmental temperature, $m_{1}$ is the varying rate of the background temperature, $m_{2}$ indicates the temperature drifting of the tested material, $t$ is the testing time.

$k=\frac{q}{4 \pi m_{2}}$

where $k$ is the thermal conductivity $(\mathrm{W} /(\mathrm{m} \cdot \mathrm{K})), q$ is the heat generated by the device. The thermal conductivity values of five types of asphalt mixture beams were measured, including the control, $2 \%$ IM8 modified, 4\% IM8 modified, 1.5\% AS4 modified and 3\% AS4 modified asphalt mixture samples, shown in Fig. 1(b). It is observed that the average thermal conductivity of control asphalt mixture samples is 1.562 $\mathrm{W} /(\mathrm{m} \cdot \mathrm{K})$. The average thermal conductivities of $1.5 \%$ AS4 modified and 3\% AS4 modified asphalt mixture samples are $1.651 \mathrm{~W} /(\mathrm{m} \cdot \mathrm{K})$ and $1.731 \mathrm{~W} /(\mathrm{m} \cdot \mathrm{K})$, respectively. The average thermal conductivities of $2 \%$ IM8 modified and 4\% IM8 modified asphalt mixture samples are $1.886 \mathrm{~W} /(\mathrm{m} \cdot \mathrm{K})$ and $2.033 \mathrm{~W} /(\mathrm{m} \cdot \mathrm{K})$. Therefore, the carbon fibers could increase the thermal conductivity of asphalt mixture samples. Additionally, the thermal conductivity value of the asphalt mixture sample increases with raising the content of carbon fibers. 


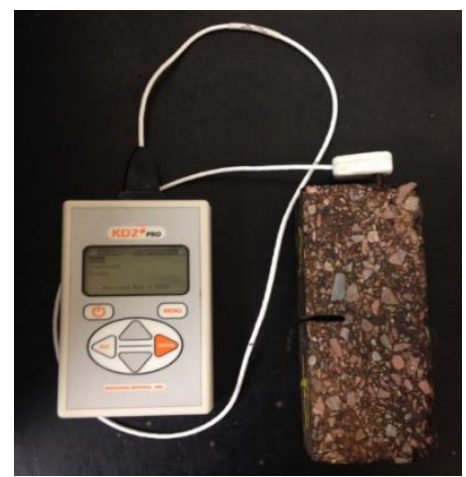

(a)

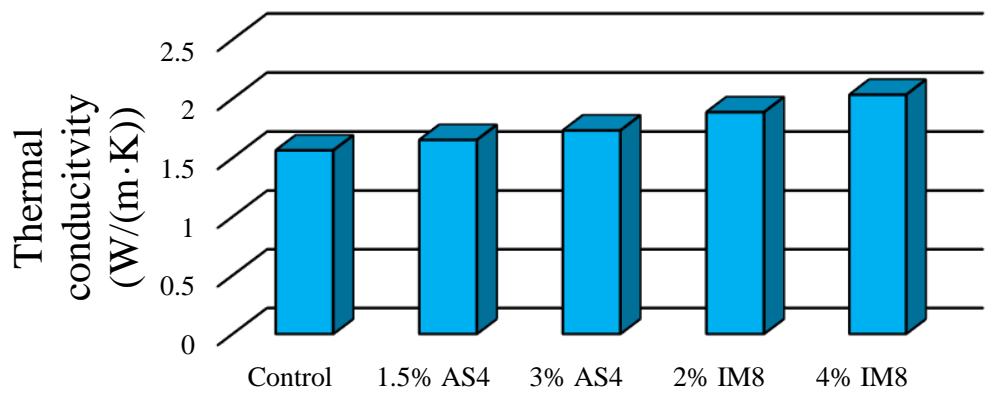

(b)

Figure 1. Thermal conductivity measurement of non-fractured asphalt mixture beams: (a) sample and device; (b) thermal conductivity data of tested samples.

\section{Electrical conductivity of asphalt mixture beams}

The electrical resistivity measurements were conducted on five different types of prepared beam samples at room temperature, displayed in Fig. 2(a). Two copper electrodes were located on the two sides of the sample to measure the electrical resistance. Then the electrical resistivity of the sample was calculated by Equation (3):

$\rho=\frac{R \times S}{L}$

where $\rho$ indicates the electrical resistivity $(\Omega \cdot m), R$ denotes the measured electrical resistance $(\Omega)$, $S$ is the cross-sectional area and $L$ is the length of the beam samples. The measured electrical resistivity values of prepared samples are plotted in Fig. 2(b). It is observed that the average electrical resistivity of control samples is about $38.5 \Omega \cdot m$. The average electrical resistivity of $1.5 \%$ and $3 \%$ AS4 modified asphalt mixture samples are approximately 29.8 and $26.3 \Omega \cdot m$. In addition, the average electrical resistivity of $2 \%$ and $4 \%$ IM8 modified asphalt mixture samples are around 19.3 and $15.4 \Omega \cdot m$. Therefore, both carbon fiber AS4 and IM8 could decrease the electrical resistivity of the asphalt mixture samples.

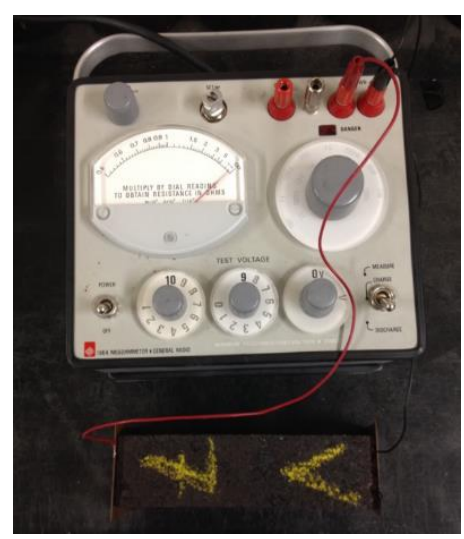

(a)

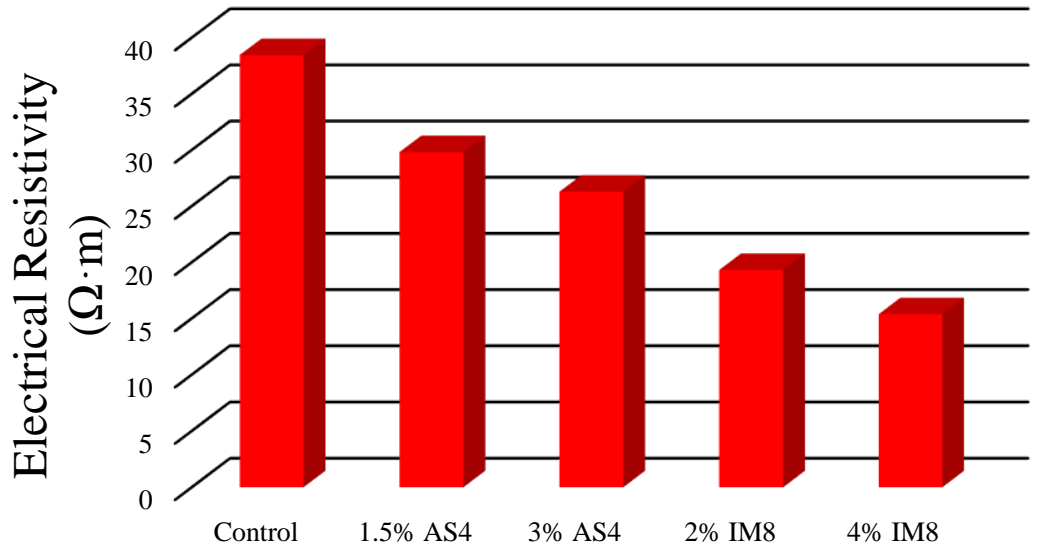

(b)

Figure 2. Electrical resistivity measurement of non-fractured asphalt mixture beams: (a) sample and device; (b) electrical resistivity data of tested samples. 


\section{Original fracture strength of asphalt mixture beams}

The control and carbon fiber modified asphalt mixture beams were used to investigate the original fracture strength (peak load). The sample was placed on a modified bending beam fixture with an elastic foundation instead of three-point bending support. The experimental results showed that the average original peak loads of the 2\% IM8 modified asphalt mixture samples reduced by $19.3 \%$ compared with the control samples. The average original peak loads of the 4\% IM8 modified asphalt mixture samples decreased by 4.7\%. The average original peak loads of the $1.5 \%$ AS4 modified asphalt mixture samples increased by $2.9 \%$. The average original peak loads of the 3\% AS4 modified asphalt mixture samples decreased by $16.8 \%$. Overall, IM8 and AS4 decreased the original strength of asphalt mixture beams. The main reason could be the carbon fibers separated the bonding of binder and aggregates to some degrees.

\section{FRACTURE-MICROWAVE HEALING INVESTIGATION OF ASPHALT MIXTURE SAMPLES WITH ELASTIC FOUNDATION MODIFIED BEAM BENDING TEST \\ 4.1 Mechanism of microwave healing of asphalt mixture}

The carbon fibers have the ability to absorb the energy when locating in the microwave field. When absorbing the energy, the temperature of the carbon fibers increase. Then the heat is transferred to the asphalt and aggregate. In this transfer process, the temperature-dependent asphalt behaves as Newtonian flow to fill the cracks in the mixture. In the microscale, the crack healing process could be regarded as a combination of capillary flow induced by surface tension force, gravity of liquid asphalt and friction between aggregate particles and flowing asphalt. Once the binder flow into microcrack space, the molecular diffusion and rebinding process will take place to recover the adhesion strength. The recovered strength was mainly from two aspects. One is the molecules diffusion in asphalt, the other is the rebinding between asphalt and aggregates. Fig. 3 displays the mechanism of microwave healing of asphalt mixture. In this study, the healing effect of carbon fibers modified asphalt mixture was investigated in the following sections.

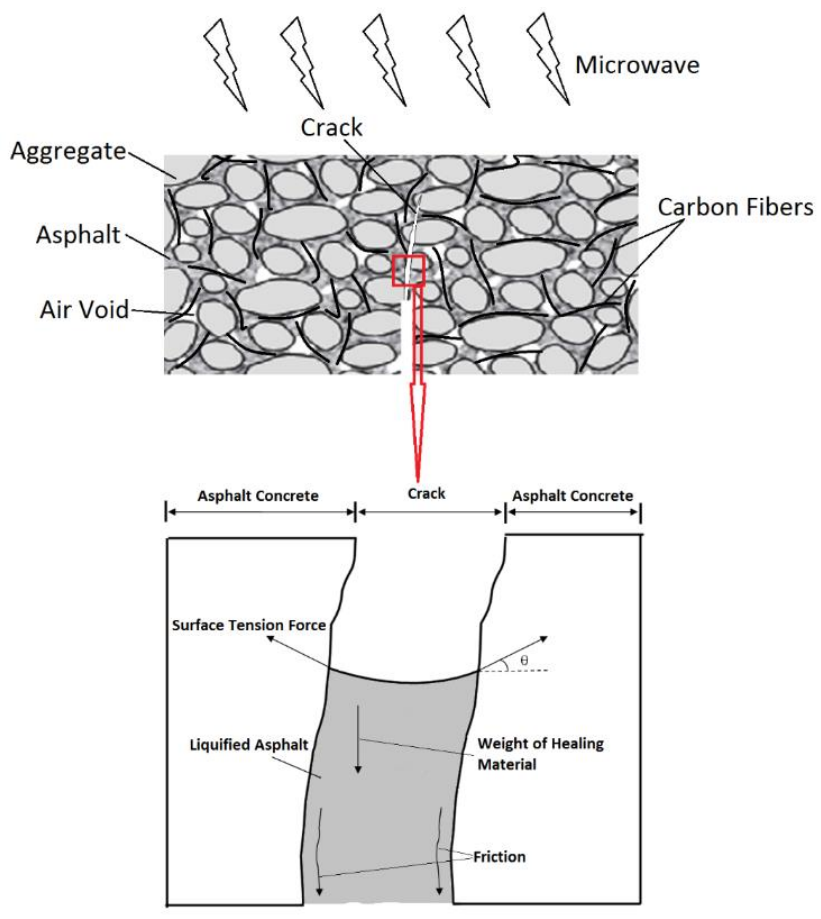


Figure 3. Schematic demonstration of microwave healing mechanism for carbon fibers modified asphalt mixture.

\section{Fracture-microwave healing tests of asphalt mixture samples}

In the first place, the induction heater generating electromagnetic (EM) energy with frequency of $120 \mathrm{kHz}$ to $160 \mathrm{kHz}$ was used to heat the carbon fiber modified asphalt mixture before the samples were heated by the microwave. The temperature of the carbon fiber modified samples did not increase. Therefore, it was concluded that the carbon fiber used in this study could not absorb the EM energy with relatively low frequency of $120 \mathrm{kHz}$ to $160 \mathrm{kHz}$. Then the author attempted to utilize different EM energy with higher frequency. As known, the frequency of the microwave generated by the oven was about $2450 \mathrm{MHz}$. Hence, the healing performance of carbon fibers in the asphalt mixture was investigated by the cyclic fracturemicrowave healing test. Briefly speaking, the test contains two parts, the sample fractured test and sample microwave healed test. In the sample fractured test, the tested sample was first placed in a freezer for 6 hours to assure an internal temperature of $-10{ }^{\circ} \mathrm{C}$. Then the beam was located on a modified elastic foundation instead of the regular three-point support, shown in Fig. 4. The crack along the vertical direction of the tested beam was generated by applying a descending load with a speed of $0.5 \mathrm{~mm} / \mathrm{min}$. During the test, the loading machine was halted manually as long as the applying load increased to the maximum value (peak load). The peak load, crack tip opening displacement (CTOD) and testing time were recorded automatically.

During the sample microwave healing process, the fractured sample was located into a $1100 \mathrm{w}$ microwave oven, heating for 2 minutes. The carbon fiber inside the sample absorbed the microwave energy and the surface temperature went up to around $100{ }^{\circ} \mathrm{C}$ to heal the crack. Later, the sample was taken out, being healed for another 30 minutes until its temperature decreased to room temperature. Then the healed sample was placed into the freezer for 6 hours and the load was applied on the sample again. This repeated procedure was called cyclic fracture-microwave healing tests. In this research, six cycles of fracturemicrowave healing tests were conducted to investigate the healing effect of the control, IM8 and AS4 carbon fiber modified asphalt mixture samples.

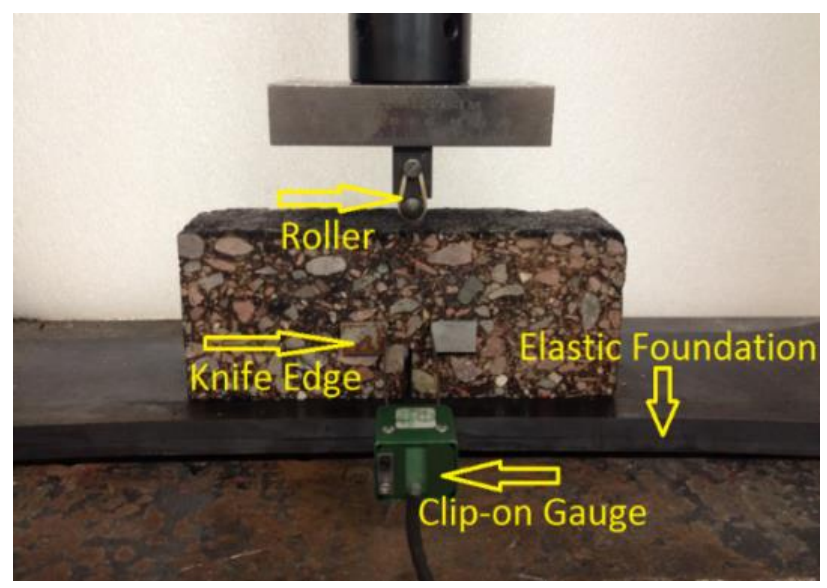

(a)

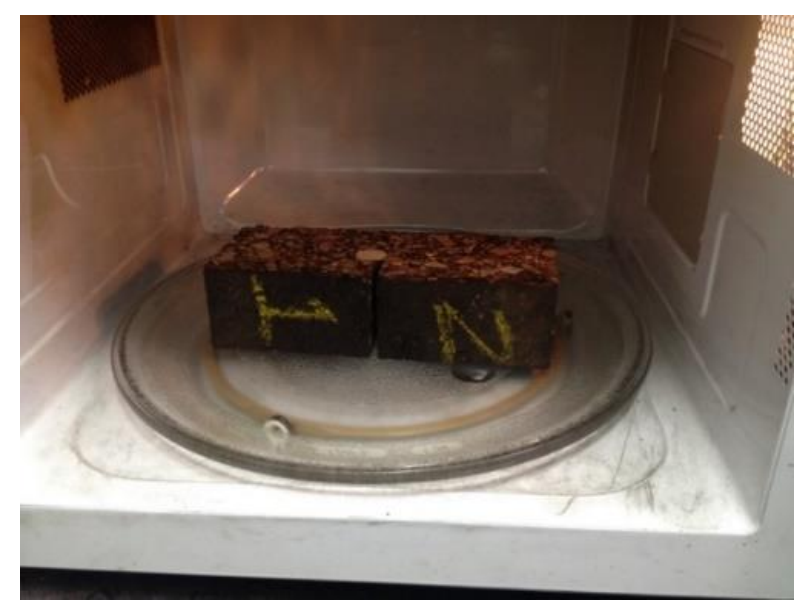

(b)

Figure 4 Demonstration of fracture-microwave healing test: (a) Modified bending test of asphalt mixture beam with elastic foundation; (b) Microwave healing of asphalt mixture beam sample.

Fracture-microwave healing test results of asphalt mixture samples 
In this study, the recovered strengths (recovered peak loads) were adopted to evaluate the healing effect of the carbon fiber modified asphalt samples. Table 2 exhibits the peak loads of asphalt mixture beam samples by the cyclic fracture-microwave healing tests, including control, 2\% and 4\% IM8, 1.5\% and 3\% AS4 carbon fiber modified asphalt mixture beams, respectively. The ratios of recovered peak loads (recovered peak load divided by original peak load) of all the tested beam samples are recorded in Table 3 . For the control asphalt mixture samples, it is observed that the range of original peak loads is from $4300 \mathrm{~N}$ to 4600 $\mathrm{N}$ (average value $4560 \mathrm{~N}$ ), reducing to the range of $1200 \mathrm{~N}$ to $1800 \mathrm{~N}$ after five fracture-microwave healing cycles. The average ratio of recovered peak loads after the first cycle remains $55.4 \%$, reducing to $48.9 \%$, $41.8 \%, 35.0 \%$ and $31.9 \%$ cycle by cycle. For the $2 \%$ IM8 modified asphalt mixture samples, the peak loads are in the range of $3500 \mathrm{~N}$ to $3800 \mathrm{~N}$ (average value $3678 \mathrm{~N}$ ) at the first loading, decreasing to the range of $2900 \mathrm{~N}$ to $3300 \mathrm{~N}$ at the sixth loading. The average ratios of recovered peak loads decrease from $92.0 \%$, $90.8 \%, 88.8 \%, 87.6 \%$ to $85.7 \%$ during five cycles. For the $4 \%$ IM8 modified asphalt mixture samples, the scope of original peak loads is from $3700 \mathrm{~N}$ to $4400 \mathrm{~N}$ (average value $4345 \mathrm{~N}$ ). After five cycles of loading, the recovered peak loads float from $2200 \mathrm{~N}$ to $2400 \mathrm{~N}$. The average ratios of recovered peak loads reduce from $67.2 \%$ to $54.4 \%$ in the five cycles. For the $1.5 \%$ AS4 modified asphalt mixture samples, the range of original peak loads is from $4400 \mathrm{~N}$ to $5000 \mathrm{~N}(4692 \mathrm{~N})$, lowering to about $2200 \mathrm{~N}$ at the sixth loading. The average ratios of recovered peak loads are $91.5 \%$ after the first cycle and $45.5 \%$ after the fifth cycle. For the 3\% AS4 modified asphalt mixture samples, the original peak loads are in the scope of $3500 \mathrm{~N}$ to 4000 $\mathrm{N}$ (average value $3796 \mathrm{~N}$ ) while the recovered peak loads are between $2800 \mathrm{~N}$ and $3200 \mathrm{~N}$ at the sixth loading. In addition, the average ratios of recovered peak loads decrease from $90.4 \%$ to $78.1 \%$ after the fifth cycle. Both the added IM8 and AS4 could improve the microwave healing performance of asphalt mixture. The microwave healing performance of $2 \%$ IM8 modified asphalt mixture was much better than the $4 \%$ IM8 modified asphalt mixture. It is caused that high content of carbon fibers (more than $2 \%$ of mixture weight) may have negative impact on the Newtonian flow of the asphalt during the microwave healing process. This study demonstrates a promising microwave healing technique with carbon fiber modified asphalt mixtures.

Table 2. Peak loads (N) of asphalt mixture beams during cyclic fracture-microwave healing tests.

\begin{tabular}{|l|l|l|l|l|l|l|}
\hline Sample & $1^{\text {st }}$ loading & $2^{\text {nd }}$ loading & $3^{\text {rd }}$ loading & $4^{\text {th }}$ loading & $5^{\text {th }}$ loading & $6^{\text {th }}$ loading \\
\hline Control No.1 & 4349.5 & 2739.3 & 2103.7 & 1978.7 & 1308.0 & 1206.9 \\
\hline Control No.2 & 4799.3 & 2363.6 & 2449.7 & 1724.9 & 1610.0 & 1436.1 \\
\hline Control No.3 & 4529.8 & 2447.1 & 2138.8 & 1990.3 & 1878.5 & 1723.5 \\
\hline $2 \%$ IM8 No.1 & 3554.4 & 3285.1 & 3184.5 & 3098.0 & 3068.5 & 2957.1 \\
\hline $2 \%$ IM8 No.2 & 3705.6 & 3370.3 & 3397.0 & 3283.4 & 3238.0 & 3234.7 \\
\hline 2\% IM8 No.3 & 3773.1 & 3501.6 & 3436.7 & 3421.9 & 3356.8 & 3268.4 \\
\hline $4 \%$ IM8 No.1 & 4312.3 & 2728.9 & 2611.8 & 2538.2 & 2428.9 & 2281.4 \\
\hline $4 \%$ IM8 No.2 & 4930.7 & 2932.4 & 2746.6 & 2606.7 & 2332.1 & 2311.6 \\
\hline $4 \%$ IM8 No.3 & 3792.9 & 2986.7 & 2768.8 & 2754.1 & 2520.9 & 2399.7 \\
\hline $1.5 \%$ AS4 No.1 & 4934.7 & 4063.2 & 3869.7 & 3319.1 & 2414.8 & 2010.8 \\
\hline $1.5 \%$ AS4 No.2 & 4688.5 & 4423.4 & 4199.0 & 3784.6 & 2887.7 & 2255.8 \\
\hline $1.5 \%$ AS4 No.3 & 4452.2 & 4352.3 & 3842.77 & 3649.7 & 2846.2 & 2113.2 \\
\hline $3 \%$ AS4 No.1 & 3597.6 & 3106.6 & 3126.5 & 3375.1 & 3121.4 & 2875.2 \\
\hline $3 \%$ AS4 No.2 & 3857.2 & 3634.0 & 3462.3 & 3393.6 & 3304.3 & 3188.3 \\
\hline
\end{tabular}




\begin{tabular}{|l|l|l|l|l|l|l|}
\hline $3 \%$ AS4 No.3 & 3931.8 & 3566.7 & 3377.6 & 3171.3 & 2846.8 & 2814.0 \\
\hline
\end{tabular}

Table 3. Ratio (\%) of recovered peak loads of asphalt mixture beams during cyclic fracturemicrowave healing tests

\begin{tabular}{|l|l|l|l|l|l|}
\hline Sample & $\begin{array}{l}\text { 2nd loading } \\
\text { after 1 cycle }\end{array}$ & $\begin{array}{l}\text { 3rd loading } \\
\text { after 2 cycles }\end{array}$ & $\begin{array}{l}\text { 4th loading } \\
\text { after 3 cycles }\end{array}$ & $\begin{array}{l}\text { 5th loading } \\
\text { after 4 cycles }\end{array}$ & $\begin{array}{l}\text { 6th loading } \\
\text { after 5 cycle }\end{array}$ \\
\hline Control No.1 & $63.0 \%$ & $48.4 \%$ & $45.5 \%$ & $30.1 \%$ & $27.7 \%$ \\
\hline Control No.2 & $49.2 \%$ & $51.0 \%$ & $35.9 \%$ & $33.5 \%$ & $29.9 \%$ \\
\hline Control No.3 & $54.0 \%$ & $47.2 \%$ & $43.9 \%$ & $41.5 \%$ & $38.0 \%$ \\
\hline $\begin{array}{l}\text { Average of control } \\
\text { samples }\end{array}$ & $55.4 \%$ & $48.9 \%$ & $41.8 \%$ & $35.0 \%$ & $31.9 \%$ \\
\hline 2\% IM8 No.1 & $92.4 \%$ & $89.6 \%$ & $87.2 \%$ & $86.3 \%$ & $83.2 \%$ \\
\hline 2\% IM8 No.2 & $91.0 \%$ & $91.7 \%$ & $88.6 \%$ & $87.4 \%$ & $87.3 \%$ \\
\hline 2\% IM8 No.3 & $92.8 \%$ & $91.1 \%$ & $90.7 \%$ & $89.0 \%$ & $86.6 \%$ \\
\hline $\begin{array}{l}\text { Average of 2\% } \\
\text { IM8 samples }\end{array}$ & $92.0 \%$ & $90.8 \%$ & $88.8 \%$ & $87.6 \%$ & $85.7 \%$ \\
\hline 4\% IM8 No.1 & $63.3 \%$ & $60.6 \%$ & $58.9 \%$ & $56.3 \%$ & $52.9 \%$ \\
\hline 4\% IM8 No.2 & $59.5 \%$ & $55.7 \%$ & $52.9 \%$ & $47.3 \%$ & $46.9 \%$ \\
\hline 4\% IM8 No.3 & $78.7 \%$ & $73.0 \%$ & $72.6 \%$ & $66.5 \%$ & $63.3 \%$ \\
\hline $\begin{array}{l}\text { Average of 4\% } \\
\text { IM8 samples }\end{array}$ & $67.2 \%$ & $63.1 \%$ & $61.5 \%$ & $56.7 \%$ & $54.4 \%$ \\
\hline 1.5\% AS4 No.1 & $82.3 \%$ & $78.4 \%$ & $67.3 \%$ & $48.9 \%$ & $40.7 \%$ \\
\hline 1.5\% AS4 No.2 & $94.3 \%$ & $89.6 \%$ & $80.7 \%$ & $61.6 \%$ & $48.1 \%$ \\
\hline $1.5 \%$ AS4 No.3 & $97.8 \%$ & $86.3 \%$ & $82.0 \%$ & $63.9 \%$ & $47.5 \%$ \\
\hline $\begin{array}{l}\text { Average of 1.5\% } \\
\text { AS4 samples }\end{array}$ & $91.5 \%$ & $84.8 \%$ & $76.7 \%$ & $58.1 \%$ & $45.4 \%$ \\
\hline 3\% AS4 No.1 & $86.4 \%$ & $86.9 \%$ & $93.8 \%$ & $86.8 \%$ & $79.9 \%$ \\
\hline 3\% AS4 No.2 & $94.2 \%$ & $89.8 \%$ & $88.0 \%$ & $85.7 \%$ & $82.7 \%$ \\
\hline 3\% AS4 No.3 & $90.7 \%$ & $85.9 \%$ & $80.7 \%$ & $72.4 \%$ & $71.6 \%$ \\
\hline $\begin{array}{l}\text { Average of 3\% } \\
\text { AS4 samples }\end{array}$ & $90.4 \%$ & $87.5 \%$ & $87.5 \%$ & $81.6 \%$ & $78.1 \%$ \\
\hline
\end{tabular}

\section{SUMMARY AND CONCLUSIONS}

In this research, carbon fibers IM8 were hand chopped to $0.25 \mathrm{inch}$, dry-mixed with aggregates and asphalt binder to produce the asphalt mixture. AS4 were pre-chopped to 0.25 inch, wet-mixed with asphalt binder. Then the binder with added AS4 were mixed with aggregates to obtain the mixture. The thermal conductivity and electrical resistivity of the control and carbon fiber modified asphalt mixture samples were measured. In addition, the cyclic fracture-light healing tests were implemented to evaluate the microwave healing effect of samples, including control, $2 \%$ and $4 \%$ IM modified, 1.5\% and 3\% AS4 modified asphalt mixture.

The measurement results of the thermal conductivity of the samples indicated that the carbon fiber, as a modifier, could increase the thermal conductivity of the asphalt mixture. Additionally, the carbon fiber has the ability to decrease the electrical resistivity of the mixture. Moreover, the carbon fibers decrease the original strength of the asphalt mixture because of the bonding separation between the asphalt binder and aggregates. Finally, the results of the cyclic fracture-microwave healing test indicated that the carbon fibers, containing IM8 and AS4, both achieved superior microwave healing performance. However, 2\% IM8 
modified asphalt mixture overperformed than 4\% IM8 modified asphalt mixture. Since a higher carbon fiber content (more than 2\%) may lead to overcompacted samples with added large fiber volume. The air void may reduce, limiting the binder Newtonian flow in the microwave healing process.

\section{ACKNOWLEDGEMENT}

The authors would like to acknowledge the State of Michigan Research Excellence Fund program and Electroactive Multiphase Material System with Enhanced Mechanical Properties and Self-Healing and Energy-Harvesting Functions for financial support. The authors also thank David Porter, Paul Fraley, Robert Fritz and Henrique de Melo e Silva at Michigan Technological University for their help in experimental work.

\section{REFERENCE}

Bhasin, A., et al. (2010). "Use of molecular dynamics to investigate self-healing mechanisms in asphalt binders." Journal of Materials in Civil Engineering 23(4): 485-492.

Cao, M.-S., et al. (2010). "The effects of temperature and frequency on the dielectric properties, electromagnetic interference shielding and microwave-absorption of short carbon fiber/silica composites." Carbon 48(3): 788-796.

D5334-14, A. (2014). Standard Test Method for Determination of Thermal Conductivity of Soil and Soft Rock by Thermal Needle Probe Procedure, ASTM.

García, Á. (2012). "Self-healing of open cracks in asphalt mastic." Fuel 93: 264-272.

García, Á., et al. (2012). "A simple model to define induction heating in asphalt mastic." Construction and Building Materials 31: 38-46.

García, Á., et al. (2012). "Optimization of composition and mixing process of a self-healing porous asphalt." Construction and Building Materials 30: 59-65.

Hashisho, Z., et al. (2009). "Role of functional groups on the microwave attenuation and electric resistivity of activated carbon fiber cloth." Carbon 47(7): 1814-1823.

Khattak, M. J., et al. (2012). "The impact of carbon nano-fiber modification on asphalt binder rheology." Construction and Building Materials 30: 257-264.

Kim, Y.-R., et al. (2003). "Fatigue and healing characterization of asphalt mixtures." Journal of Materials in Civil Engineering 15(1): 75-83.

Liu, Q., et al. (2010). "Induction heating of electrically conductive porous asphalt concrete." Construction and Building Materials 24(7): 1207-1213.

Liu, X. and S. Wu (2011). "Study on the graphite and carbon fiber modified asphalt concrete." Construction and Building Materials 25(4): 1807-1811.

Liu, X., et al. (2008). "Self-monitoring application of asphalt concrete containing graphite and carbon fibers." Journal of Wuhan University of Technology-Mater. Sci. Ed. 23(2): 268-271.

Ma, B., et al. (2014). "Applying Method of Moments to Model the Reliability of Deteriorating Performance to Asphalt Pavement under Freeze-Thaw Cycles in Cold Regions." Journal of Materials in Civil Engineering 27(1): 04014103.

Qing, Y., et al. (2010). "Electromagnetic and microwave absorption properties of carbonyl iron and carbon fiber filled epoxy/silicone resin coatings." Applied Physics A 100(4): 1177-1181.

Qiu, J., et al. (2012). "Evaluating self healing capability of bituminous mastics." Experimental mechanics 52(8): 1163-1171.

Shen, S., et al. (2010). "Characterization of fatigue and healing in asphalt binders." Journal of Materials in Civil Engineering 22(9): 846-852.

$\mathrm{Si}$, W., et al. (2014). "Reliability-based assessment of deteriorating performance to asphalt pavement under freeze-thaw cycles in cold regions." Construction and Building Materials 68: 572-

Vacquier, V. (1985). "The measurement of thermal conductivity of solids with a transient linear heat source on the plane surface of a poorly conducting body." Earth and planetary science letters 74(2): 275-279. 
Wang, Z., et al. (2016). "Integrated Computational-Experimental Approach for Evaluating Recovered Fracture Strength after Induction Healing of Asphalt Concrete Beam Samples." Construction and Building Materials, accepted.

Yang, T., et al. (2011). "Experimental study on carbon fiber tape-based deicing technology." Journal of Cold Regions Engineering 26(2): 55-70.

You, Z., et al. (2009). "Dynamic modulus simulation of the asphalt concrete using the X-ray computed tomography images." Materials and structures 42(5): 617-630.

Zhao, N., et al. (2006). "Microwave absorbing properties of activated carbon-fiber felt screens (verticalarranged carbon fibers)/epoxy resin composites." Materials Science and Engineering: B 127(2): 207-211. 